\title{
Derecho, delito y pena. \\ Una mirada desde la Filosofía del Derecho de Hegel
}

\author{
Right, crime and punishment. \\ A look from Hegel's Philosophy of Right
}

Martina Lassalle*

Resumen: El presente trabajo se propone recuperar los principales aportes de Hegel sobre el problema del delito y la pena en el esquema que presenta en la Filosofía del Derecho, haciendo un continuo esfuerzo por enmarcarlos en su compleja propuesta filosófica más general, es decir, en el marco del movimiento dialéctico con el que piensa el continuo hacerse de las sociedades y los sujetos. Buscaremos principalmente mostrar el modo en que Hegel rechaza las concepciones utilitaristas sobre la pena (prevención, disuasión, corrección) para proponer una idea del castigo en tanto retribución, pero donde retribución adquiere un sentido peculiar que, consideramos, sólo puede ser leído a la luz de su dialéctica y de su singular concepción del derecho.

Palabras Claves: Hegel, Derecho, Delito, Pena.

\section{Abstract}

This article seeks to recover Hegel's main contributions regarding the problem of crime and punishment in the scheme he presents in Philosophy of Right, making a continuous effort to frame them in his most general complex philosophical proposal, i.e., in the framework of the dialectical movement with which he thinks the permanent making of societies and subjects. We will mainly aim to show the way in which Hegel rejects utilitarian conceptions about punishment (prevention, dissuasion, correction) to propose an idea of punishment as retribution, but where retribution acquires a peculiar sense that, we consider, can only be read in the light of his dialectics and his singular conception of right.

Key Words: Hegel, Right, Crime, Punishment

* Licenciada en Sociología por la Universidad de Buenos Aires y doctoranda en Ciencias Sociales en dicha casa de estudios. Becaria doctoral UBACyT en el marco del proyecto: "Los usos socio-políticos de la violencia. Hacia un análisis cultural de la cuestión criminal en la Argentina contemporánea" dirigido por Sergio Tonkonoff en el Instituto de Investigaciones Gino Germani. Ayudante de primera en la materia "Psicología Social" de la carrera de Sociología de la UBA. Correo electrónico: lassallemartina@gmail.com 


\section{A modo de introducción}

El lugar que Hegel otorga al problema del delito y de la pena dentro de la Filosofía del Derecho es ciertamente un lugar privilegiado. Y esto por cuanto que, en los planteos de Hegel, sin delito y sin el posterior castigo, las personas jurídicas se mantendrían en una relación de exterioridad respecto del derecho, es decir, no se constituirían como sujetos morales. De manera más general, habría que afirmar, en primer lugar, que sin estas categorías Hegel no puede pensar el desarrollo dialéctico del concepto de derecho, preocupación que atraviesa todo ese trabajo. Se verá entonces que se trata de una problemática clave para analizar el desarrollo del Estado Moderno. De ahí que creemos que esta preocupación resulta ciertamente inabordable si no es leída en el marco y a la luz de su esquema filosófico más general. Existen importantes trabajos, muchos de los cuales hemos tomados como insumos para este escrito, que abordan el problema del delito y la pena en Hegel. No obstante, todos ellos tienen como objetivo pensar ciertos aspectos de esta problemática, sin necesariamente enmarcarla en la preocupación que constituye la espina dorsal de la Filosofía del Derecho: el desarrollo (dialéctico) de la voluntad libre en sí y para sí [an und für sich].

La importancia de leer el problema del delito y la pena, o cualquier otro problema específico, en el marco de los planteos conceptuales más generales que le sirven de sustento, no parece ser una excepción para el caso del Hegel. ¿Cómo entender las reflexiones de Marx sobre el problema del delito y el castigo sin dar cuenta de los conceptos fundamentales con los que piensa un modo de producción? De igual modo, ¿cómo comprender la propuesta de Durkheim para pensar este problema sin conocer las categorías teóricas más generales con las que analiza las dinámicas sociales? Incluso, viniendo más cerca en el tiempo, ¿cómo pensar la categoría de castigo en Foucault sin comprender lo que entiende por relación de poder y, de manera más general, por dispositivo?

Es en este marco que el presente trabajo se propone recuperar los principales aportes de Hegel sobre el problema del delito y la pena en el esquema que presenta en la Filosofía del Derecho, haciendo un continuo esfuerzo por enmarcarlos en su compleja propuesta filosófica más general, es decir, en el marco del movimiento dialéctico con el que piensa el continuo hacerse de 
las sociedades y los sujetos. Buscaremos principalmente mostrar el modo en que Hegel rechaza las concepciones utilitaristas sobre la pena (prevención, disuasión, corrección) para proponer una idea del castigo en tanto retribución, pero donde retribución adquiere un sentido peculiar que, consideramos, sólo puede ser leído a la luz de su dialéctica y de su singular concepción del derecho.

\section{E1 derecho como reino de la libertad realizada: punto de partida y de llegada}

"La ciencia filosófica del derecho tiene como finalidad la idea de derecho, el concepto de derecho y su realización” (\1). “(...) el sistema del derecho es el reino de la libertad realizada; el mundo del espíritu que se produce a sí mismo como segunda naturaleza" (\4). Tales proposiciones (iniciales) indican con claridad la preocupación central que atraviesa toda la Filosofía del Derecho de Hegel: la realización de la idea de libertad, la realización de la voluntad libre. ${ }^{1}$ Siendo éste el hilo conductor de las reflexiones presentadas en dicho tratado filosófico, el problema del delito y el castigo - pero también otros como el de la subjetividad individual, la familia, la sociedad civil- pueden, y deben, ser aprehendidos teniendo como horizonte que es la realización del concepto de derecho - esto es, el reino de la libertad realizada- el problema general donde se enmarcan esos desarrollos. Ahora bien, antes de abordar directamente el asunto que aquí nos ocupa, creemos importante remarcar algunas cuestiones sobre el tratamiento filosófico que Hegel da a la idea de derecho. En primer lugar, puede notarse que Hegel se encuentra lejos de concebir el derecho como un conjunto de reglas de comportamiento (del tipo que sea) que necesariamente limitan las libertades individuales para posibilitar la vida en sociedad. Aunque con variantes, esta concepción se encuentra próxima tanto a los desarrollos de Kant, como a las propuestas del iusnaturalismo. Según Hegel, estas perspectivas definen negativamente el aspecto principal del derecho puesto que subrayan una limitación de la libertad o del arbitrio individual. Por el contrario, como hemos mencionado anteriormente,

\footnotetext{
${ }^{1}$ Ver Hegel, Georg Wilhelm Friedrich, Fundamentos de la filosofía del derecho, traducción de Alfredo Llanos, Buenos Aires, Leviatán, 2015, \1, p. 71 [Grundlinien der Philosophie des Rechts, Suhrkamp Verlag, 1976].
} 
el derecho aparece en la propuesta hegeliana como el ámbito propio de realización de la voluntad libre -realización que sólo puede ser tal en el marco del Estado-, ${ }^{2}$ con lo cual, no se encuentra reducido al mero derecho formal. De aquí se desprenden dos consideraciones que son ciertamente importantes de remarcar. En primer lugar, que, según Hegel, la libertad se desarrolla dialécticamente, por lo que atraviesa distintas configuraciones que se van superando entre sí en este proceso de realización: “(...) el concepto se desarrolla por sí mismo y es un progreso inmanente y un producto de sus determinaciones (...)" (\$ 31). En este sentido, la esfera del derecho formal no es más que una de las configuraciones que el concepto [Begriff] asume en este proceso dialéctico, pero no puede confundirse con el concepto de derecho como tal, el cual ciertamente incluye el derecho formal, aunque de una forma peculiar. Volveremos sobre esta cuestión más adelante ya que será nuestro punto de partida para abordar el problema del delito y la pena.

En segundo término, que Hegel otorga un lugar central a la categoría voluntad para pensar el derecho. Y esto por cuanto la voluntad es para Hegel el punto de partida del dominio del derecho. "La voluntad es, pues, un modo peculiar de pensamiento capaz de volverse práctico y de convertirse en existencias espacio-temporales", 3 es el pensamiento en cuanto impulso de darse existencia, y su determinación fundamental es la de ser libre. ${ }^{4}$ Ahora bien, la libertad, que para Hegel sólo puede producirse en forma de voluntad, se va desarrollando dialécticamente, y es por eso que su despliegue tiene diferentes momentos. El derecho como mundo espiritual es el horizonte en que se efectúa

${ }^{2}$ Es preciso señalar que Hegel no concibe el estado como un aparato sino como "la totalidad de los sujetos que lo componen, quienes juntos conforman el gran sujeto colectivo" El estado aparece entonces como una intersubjetividad en su máxima expresión. Ver Dri, Rubén, "La filosofía del Estado ético. La concepción hegeliana del Estado", en Borón, Atilio (comp.), La filosofía política moderna. De Hobbes a Marx, Buenos Aires, Clacso, 2000, p. 218.

${ }^{3}$ Cordua, Carla, Explicación sucinta de la filosofía del derecho en Hegel, Santa Fé de Bogotá, Temis, 1992 , p. 7.

${ }^{4}$ Ver Hegel, Georg Wilhelm Friedrich, Fundamentos de la filosofía del derecho, ed. cit., p. 71. 
la realización socio-política de la libertad de la voluntad, ${ }^{5}$ es la forma en que la voluntad se objetiva otorgándose su propia normatividad. Y dado que para Hegel este 'otorgarse su propia ley' es un acto de libertad, la voluntad (libre) es su punto de partida. Si aceptamos lo anterior, la naturaleza no podría ser entonces fundamento del derecho. Ahora bien, como mencionamos antes, el hecho de que la voluntad sea libre no implica que esta libertad se encuentre necesariamente ya realizada. En cambio, Hegel identifica tres configuraciones que la voluntad presenta en el desarrollo de su libertad, configuraciones que, como sostiene Dri, refieren a los tres momentos de la dialéctica hegeliana: el universal abstracto o en-sí [an sich], el particular o para-sí [für sich], y el universal concreto o en-sí-para-sí [an und für sich]. ${ }^{6}$ En un primer momento (lógico, conceptual), la voluntad es inmediata, contiene el "elemento de la pura indeterminación o de la pura reflexión del yo en sí, en el cual se disuelve toda limitación, todo contenido determinado (...), la infinitud ilimitada de la absoluta abstracción o universalidad". ${ }^{7}$ Según Hegel, se está aquí frente a una libertad de tipo negativa que no es más que la negación de todo contenido, la abstracción de toda determinación, y refiere al ámbito del entendimiento. El sujeto es, en esta primera etapa, una persona; es decir, un individuo meramente portador de derechos jurídicos que sólo puede darse existencia a sí mismo a través de la toma de posesión de una cosa particular externa. Se trata, según Hegel, de la configuración más pobre en la realización del sujeto individual. ${ }^{8}$ En un segundo momento de la dialéctica del concepto de libertad, la voluntad,

\footnotetext{
${ }^{5}$ Sobre este punto, se recomienda la lectura de Amengual, Gabriel, La moral como derecho. Estudios sobre la moralidad en la Filosofía del Derecho de Hegel, Madrid, Trotta, 2001.

"Ver Dri, Rubén, "La filosofía del Estado ético. La concepción hegeliana del Estado", p. 220.

7 Ilting, Karl-Heinz, "La forma lógica y sistemática de la filosofía del derecho", en Hegel, Georg Wilhelm Friedrich, Fundamentos de la filosofía del derecho, p. 27.

${ }^{8}$ Tal como sostiene Dri, cuando la dialéctica se frena en este momento del desarrollo de la libertad (el universal abstracto) se generan, para Hegel, las peores formas de gobierno, aquellas en donde se afirma querer la igualdad absoluta, pero, en realidad, no se quiere nada positivo. Recordemos que, en esta primera configuración de la voluntad, nos encontramos frente a la libertad, pero en un sentido negativo. Observaremos que esto es crucial a la hora de analizar la esfera del derecho abstracto, y el delito como su negación. Ver Dri, Rubén, "La filosofía del Estado ético. La concepción hegeliana del Estado", p. 219.
} 
antes inmediata e indeterminada, se particulariza; "se determina como individualidad subjetiva frente a lo universal".? Aquí el sujeto se da un contenido a sí mismo, generando mediaciones que niegan la primera negatividad abstracta. El sujeto que se particulariza, que se da un contenido y un objeto, contiene la primera configuración del sujeto como persona, pero ahora como superación. Lo universal queda dividido en una parte interna, el bien, y en una parte externa, el mundo exterior. Ambas son partes de la idea, las cuales pueden desarrollarse únicamente una a través de la otra, pero la voluntad subjetiva (o moral) aún no puede reunirlas. En esta división, la idea se cumple, por un lado, "como derecho de la voluntad subjetiva y, por el otro, como derecho del mundo o de la idea implícita". ${ }^{10}$ Es preciso mencionar que "este segundo momento ya está incluido en el primero y es solo un poner lo que el primero ya es en sí", ${ }^{11}$ pues la dialéctica hegeliana concibe que todo lo que el concepto podrá ser ya se encuentra en ese primer momento, solo que aún no desarrollado. Por último, sostiene Hegel, en un tercer momento, la voluntad se presenta como libre en sí y para sí [an und für sich], reflejándose en sí misma y en el mundo exterior. Siendo la superación [Aufhebung] del segundo momento, contiene tanto a este último como al primero de ellos; no es más que la unidad de ambos, los cuales hasta ahora permanecían todavía abstractos y separados. Según el filósofo alemán, es en este momento que es posible retornar a la universalidad que toda autoconciencia es, pero habiendo incorporado las particularizaciones del segundo momento. Así, el universal se concretiza.

Cada etapa del desarrollo de la voluntad libre (desde la libertad en sentido negativo a la realización de la misma en un sentido positivo, desde su inmediatez e indeterminación a su mediatez y determinación como universal concreto) posee, según Hegel, su propio derecho dado que, como hemos mencionado antes, éste no es más que una de las determinaciones particulares en que existe la libertad en cada uno de esos momentos. Dado que aquí nos propondremos explorar el planteo hegeliano sobre el delito y la pena, posaremos nuestra mirada sobre el primer momento del desarrollo de la voluntad libre -lo que más arriba hemos llamado voluntad inmediata-,

\footnotetext{
${ }^{9}$ Hegel, Georg Wilhelm Friedrich, Fundamentos de la filosofía del derecho, \ 33, p. 91.

${ }^{10}$ Cordua, Carla, Explicación sucinta de la filosofía del derecho en Hegel, p. 32.

${ }^{11}$ Hegel, Georg Wilhelm Friedrich, Fundamentos de la filosofía del derecho, S 6, p. 74,
} 
configuración que corresponde a la esfera del derecho abstracto. Es en esta esfera en donde pueden hallarse las reflexiones de Hegel sobre este problema. El segundo y el tercer momento del proceso de determinación conceptual interno de la voluntad conciernen a la moralidad y a la eticidad respectivamente. Si bien en el presente trabajo no ahondaremos demasiado en torno a estos dos momentos, es preciso destacar que también ellos son determinaciones particulares del derecho en tanto realización de la idea de libertad. "La moralidad, la eticidad, el interés del Estado constituyen cada uno un derecho especial porque cada una de esas figuras es una determinación y existencia de la libertad". ${ }^{12}$ Esto muestra que, como sosteníamos al comienzo, la novedosa concepción hegeliana del derecho no puede reducirse - como frecuentemente ocurre en la filosofía política de su tiempo - al derecho formal, esto es, al derecho abstracto. Éste es sin duda un momento ineliminable en el proceso de desarrollo de la voluntad libre, pero de ningún modo podría agotar la noción misma de derecho con la que Hegel trabaja. De hecho, se trata de la determinación más pobre en este proceso dialéctico, determinación que se verá superada (veremos que el rol del castigo asume aquí un rol fundamental) para dar paso a la moralidad.

\section{libertad \\ III. Derecho abstracto: la propiedad como primera forma de}

La esfera del derecho abstracto es la esfera que se corresponde con el desarrollo de la voluntad en tanto persona (o personalidad, dirá Hegel), esto es, en tanto que individualidad poseedora de derechos meramente jurídicos. Dado que este primer momento en el despliegue de la voluntad libre es un momento en donde la libertad es aún una libertad negativa, en la esfera del derecho abstracto sólo hay prohibiciones jurídicas, y cualquier forma positiva de los preceptos jurídicos tiene como fundamento la prohibición (\$ 38). En esta primera configuración que asume la realización de la libertad, momento de completa inmediatez, la voluntad se exterioriza mediante su relación con la cosa, apropiándose de ella; esto es, se da existencia a sí misma como voluntad

${ }^{12}$ Ibid., $§ 30$, p. 89. 
libre a través de la propiedad. La propiedad marca el ingreso al ámbito de la juridicidad; es la primera existencia de la libertad de la persona jurídica. De allí la centralidad que ésta tiene en el desarrollo de la voluntad libre, aunque, ciertamente, está ubicada en el momento de mayor pobreza del proceso. Las tres formas en que la propiedad tiene sus determinaciones más precisas en la relación voluntad-cosa son, según Hegel, la toma de posesión inmediata en la que la voluntad existe en la cosa como algo positivo; su uso, en donde la voluntad existe en la cosa negándola; y la enajenación, cuando la voluntad se retira de la cosa y vuelve sobre su reflexión en sí ( $(53)^{13}$.

Puede verse que el ámbito de la propiedad, es decir, el de la objetivación de la voluntad a través de la cosa, no muestra una relación interpersonal, un vínculo entre distintas voluntades, sino simplemente una relación entre una voluntad y la cosa que posee. En este sentido, puesto que la realización de la persona a través de la propiedad excluye otras voluntades, ésta entra necesariamente en conflicto con la realización de las otras personas. Es precisamente el pasaje al contrato el que permite una transformación en la relación de propiedad que antes describimos; es decir, permite mediar la relación de propiedad en la que la voluntad se apropia arbitrariamente de algo para satisfacer sus deseos y necesidades. En palabras de Ricoeur, el contrato permite que "(...) salgan las voluntades de su arbitrio relativo precisamente en relación con la propiedad para elevarse al reconocimiento mutuo (...)". ${ }^{14}$ Este reconocimiento refiere estrictamente a un reconocimiento del otro como propietario, es decir, como persona. Una breve aclaración resulta pertinente

${ }^{13}$ Por ser la enajenación uno de los modos principales de la propiedad, esto es, uno de los modos de la relación entre la voluntad y la cosa, ésta es sólo posible en tanto se trate de una cosa que sea, según su naturaleza, exterior. En este sentido, Hegel indica que cualquier determinación sustancial que constituya a la persona, es decir, su cuerpo y sus facultades racionales, son inalienables. Lo mismo puede decirse de la vida: "La totalidad abarcante de la actividad exterior, la vida, no es algo externo frente a la personalidad (...) No tengo por cierto ningún derecho a enajenarla, y sólo lo tiene la idea ética, como que en ella desaparece esta inmediata personalidad y constituye su fuerza efectiva, de modo que la vida, es, la vez, como tal inmediata y también la muerte es su inmediata negatividad, por lo cual debe recibirse desde el exterior, como una cosa natural, o de una mano extraña al servicio de la idea (...)"(Ibid., \$70, p. 120).

14 Ricoeur, Paul, "Historia de la idea de justicia/3. Hegel y el derecho penal", en Archipiélago: Cuadernos de crítica de la cultura, No18-19, 1994, p. 202. 
antes de continuar nuestro abordaje sobre el contrato en dirección al problema de la injusticia y la punición. La cuestión de la igualdad se ubica en el centro de la esfera del derecho abstracto. Cabe destacar que ésta refiere aquí estrictamente a una igualdad formal, es decir, a que las voluntades son todas ellas personas, y no a una igualdad material, aspecto que aquí resulta sin duda secundario en el planteo hegeliano. ${ }^{15} \mathrm{La}$ afirmación de Hegel sobre el precepto del derecho abstracto es muy clara al respecto: "Sé una persona y respeta a los demás como personas" (\$36).

Dijimos entonces que, en el marco del contrato, los propietarios se reconocen mutuamente como tales. Es decir que yo sólo puedo participar de tal institución social en tanto sea reconocido como persona, y en tanto reconozca al otro (a los otros) con esa misma condición. De modo que el contrato no refiere ya a una relación voluntad-cosa, como veíamos en la propiedad, sino a una relación entre voluntades. El contrato transforma la relación inicial entre necesidad y satisfacción, en una relación entre querer y tener. ${ }^{16}$ Así, ya no se es propietario por la posesión directa sobre una cosa externa, sino por mi relación contractual con otro propietario, por esta relación de reconocimiento mutuo que venimos describiendo. En este marco, Hegel sostiene que la enajenación de la cosa propia ya no puede permanecer como una posibilidad -como lo era en la relación de propiedad-, sino que se vuelve necesaria para la existencia del vínculo contractual. A través de una relación de estas características, yo efectivamente enajeno mi propiedad, pero conservando mi condición de propietario pues puedo adquirir la cosa de otro contratante, quien también se dispone a enajenar su propiedad ( $(74)$. Esto se debe a que, para Hegel, este proceso de intercambio genera una modificación crucial en las cosas: éstas ya no serán consideradas por sus cualidades exteriores, por su valor de uso para utilizar el término de Marx, sino por su valor, lo cual es lo universal

${ }^{15} \mathrm{El}$ problema de la propiedad concierne directamente a la realización de la libertad, y “(...) aunque la propiedad es una institución jurídica que se desarrolla a partir de la toma de posesión de cosas singulares por ciertos individuos, qué poseo o cuánto, no pertenece a la institución". Ver Cordua, Carla, Explicación sucinta de la filosofía del derecho en Hegel, p. 47.

16 Ver Ricoeur, Paul, "Historia de la idea de justicia/3. Hegel y el derecho penal”, p. 203. 
en todas ellas. ${ }^{17}$ Dos implicancias es preciso resaltar aquí: por un lado, si es entonces el valor de la cosa lo que se transa en el contrato, los propietarios involucrados en el intercambio no sólo no pierden su condición de tales al enajenar la cosa, sino que siempre conservan, además, la misma propiedad. Y esto por cuanto, como vimos, la cosa vale por lo universal que hay en ella, es decir, por su valor. Por otro lado, y en estrecha vinculación con lo anterior, junto con la transformación que ocurre en las cosas en la esfera del contrato, también sucede una modificación en el querer mismo de las voluntades. En términos de Ricoeur, "esta cosa universal es el verdadero vis à vis del querer", ${ }^{18}$ y ya no la cosa en tanto valor de uso, como sí lo era en la inicial relación de propiedad (voluntad-cosa). Es por eso que, según el filósofo francés, este querer universalizado se eleva al "rango de voluntad común que trasciende lo arbitrario del que cada voluntad se ve conducida a desasirse". ${ }^{19}$

Ahora bien, la salida del arbitrio individual que implica la relación contractual es sin embargo parcial, pues se trata de un tipo de relación que sigue estando mediada por la propiedad. Para decirlo de otro modo, si bien el contrato eleva a la voluntad por encima de la simple toma de posesión de la cosa e instituye relaciones interpersonales, éstas siguen siendo abstractas (y no universales en sí y para sí [an und für sich]) dado que se trata de relaciones entre personas inmediatamente libres, entre individualidades que sólo poseen derechos jurídicos, y que así se reconocen. Tal como afirma Ricoeur, el vínculo a través del contrato sigue siendo de exterioridad, un vínculo de relación con las cosas, y a través de ellas. Por este motivo, el contrato pertenece en Hegel a la esfera del derecho abstracto y la arbitrariedad permanece como una de sus características salientes. Se comprende, entonces, que la voluntad común a la que da lugar el intercambio contractual no debe confundirse con la voluntad absolutamente universal, la cual sólo tiene lugar, según Hegel, en el marco de las relaciones éticas, del Estado. Podrá notarse por qué Hegel rechaza las teorizaciones de la filosofía política de su tiempo en torno al contrato, principalmente aquellas que postulan al Estado como una relación contractual -ya sea como un pacto de todos con el gran Leviatán al estilo hobbesiano, ya

${ }^{17}$ Ver Marx, Karl, El Capital: el proceso de producción del capital, Buenos Aires, Siglo XXI, 2010 , p. 47.

${ }^{18}$ Ricoeur, Paul, "Historia de la idea de justicia/3. Hegel y el derecho penal", p. 203.

${ }^{19}$ Ibid. 
sea como un pacto de todos con todos al estilo más rousseauniano. En la propuesta hegeliana, el Estado nunca puede ser el producto de un contrato o pacto pues, como vimos, éste se encuentra ligado a las relaciones de propiedad, a las relaciones con (y a través de) las cosas, lo cual no vincula sujetos entre sí, sino que delimita las voluntades. El derecho abstracto permanece en Hegel como una relación de exterioridad, como el ámbito de la realización de la libertad, pero en un sentido negativo, inmediato. Por el contrario, el ámbito del Estado es el ámbito de la realización positiva de la libertad, espacio en que los hombres se reconocen mutuamente como sujetos libres en sí y para sí [an und für sich] (y no como personas jurídicas), lugar en que la voluntad común se configura como voluntad universal. Este momento de plena realización subjetiva es de una naturaleza diferente, más elevada, dirá Hegel, que aquella realidad de las relaciones de propiedad y de los contratos, razón por la cual jamás podría surgir de un acuerdo arbitrario entre voluntades particulares. Antes bien, se trata de una realidad que es producto del desarrollo inmanente del concepto de libertad, desarrollo que, ya sabemos, se produce dialécticamente.

\section{E1 delito como violencia primera}

Las consideraciones anteriores en torno a las relaciones de propiedad y al contrato $-\mathrm{O}$, de modo más general, en torno a la configuración del derecho como derecho abstracto en el momento más indeterminado de la voluntad libre-, son el punto de partida para el abordaje de Hegel sobre el delito y el castigo. Tal como sostiene Dri, podría creerse que la mediación que introduce la relación contractual a la contradicción existente entre propietarios permite, de este modo, resolverla. ${ }^{20}$ Sin embargo, como mencionábamos, esto no sucede de este modo, y el reino del contrato sigue siendo el reino de lo arbitrario. Como vimos antes, la relación contractual no liga sujetos entre sí, sino que tiene lugar entre personas jurídicas. Allí radica, en el planteo de Hegel, el núcleo del problema de la injusticia. El elemento arbitrario (en oposición a lo racional) que permanece en la esfera del contrato, es decir, el hecho de que la voluntad

\footnotetext{
${ }^{20}$ Ver Dri, Rubén, "La filosofía del Estado ético. La concepción hegeliana del Estado", p. 220.
} 
común producida por la relación contractual no sea una voluntad absolutamente universal, sino que exista como voluntad particular por ser los contratantes personas naturales cuyo querer es generalmente caprichoso ${ }^{21}$, es lo que da lugar a que pueda existir una violación del derecho abstracto, esto es, una acción injusta. $\mathrm{Y}$ es que, en el marco de relaciones abstractas o inmediatas entre las voluntades, la coincidencia de estas voluntades particulares con la voluntad en sí (la que corresponde a este primer momento de mayor indeterminación de la libertad del cual venimos hablando, y que hemos llamado voluntad común), voluntad que sólo existe a través de ellas, es, según Hegel, completamente azarosa. El contrato es producto de un acuerdo contingente entre voluntades que se excluyen mutuamente, que no se reconocen como sujetos. Es por eso que cualquiera de ellas puede imponer sus intereses individuales, particulares, rompiendo así este acuerdo. ${ }^{22}$ La injusticia brota, según Hegel, de la contradicción misma que implica la relación contractual; es una degradación del derecho sólo en apariencia que consiste en la contraposición entre esa configuración primera del derecho (como voluntad común) y la voluntad particular, lo cual produce de este modo el derecho particular (\$82). Ahora bien, el derecho particular al que da lugar la injusticia, la cual es la negación del principio del derecho, se caracteriza por su nulidad dado que en sí mismo implica una segunda negación que restituye el derecho como real y válido. Esta restitución del derecho no es sino un momento a través del cual el principio universal se actualiza a sí mismo permitiendo superar la primera configuración del derecho como derecho abstracto, ese primer momento de libertad negativa de la voluntad. Abordaremos esta cuestión en profundidad cuando analicemos el problema del castigo.

Volvamos a la injusticia para así llegar finalmente al problema del delito. Hegel postula tres tipos de acciones injustas: la injusticia civil o no culposa, el fraude y el delito. Aunque en los tres casos nos encontramos frente a la

${ }^{21}$ Ver Cordua, Carla, Explicación sucinta de la filosofía del derecho en Hegel, p. 73.

22 Dri señala que éste es uno de los puntos claves en donde puede verse la distancia de Hegel respecto del contractualismo: dado que el contrato es siempre un acuerdo (arbitrario, contingente) entre particulares, éste no podría ser el fundamento del Estado pues "por más que se sumen particulares nunca se obtendrá lo universal o lo general". Ver Dri, Rubén, "La filosofía del Estado ético. La concepción hegeliana del Estado", p. 222. 
contraposición entre una voluntad particular y la voluntad común a la que dio lugar el contrato, Hegel marca una distinción fundamental entre las dos primeras y la última forma de violación del derecho abstracto. En el caso de la injusticia civil y el fraude, estamos frente a voluntades particulares que comenten una falta de manera involuntaria, o que simulan respetar el derecho, pero lo vulneran. En ambos tipos de acciones injustas, incluso en el caso del fraude, el derecho continúa siendo reconocido, es tratado como válido, aun cuando se actúe de forma contraria al mismo. ${ }^{23}$ Dado este reconocimiento de la validez del derecho, tanto la injusticia no culposa como el fraude reclaman, más que castigo penal, la regulación y el restablecimiento de los derechos afectados -vinculados a la esfera del derecho civil. ${ }^{24}$

Será sobre la tercera forma de acción injusta donde pondremos nuestra atención, por cuanto, para Hegel, es el delito el que establece al derecho como nulo o inválido y, por tanto, reclama una pena. Si, como vimos, el derecho implica siempre un acto de libertad por parte de la voluntad (libertad que en la esfera del derecho abstracto aún no se encuentra en su realización plena), su ataque es entonces un ataque directo a la realización de esa libertad. Los atentados a la propiedad (robo, hurto, etc.) son en Hegel los ejemplos prototípicos para pensar esta cuestión dado que realiza su análisis en el marco de la esfera del derecho abstracto, esfera en la cual la persona adquiere existencia real primero a través de la propiedad y luego a través del contrato. No obstante, Hegel menciona que el perjurio, el delito contra el Estado, las falsificaciones de moneda e instrumentos de cambio, entre otros, son crímenes que también se caracterizan por la invalidación o no reconocimiento del derecho (Obs. \95)-independientemente de que la intensidad con la que se ataca la libertad sea variable en cada caso: sin duda, no resulta igual un robo que un asesinato, por ejemplo. El delito comporta entonces la negación del derecho, su destrucción, lo cual tiene, por así decirlo, dos aspectos. Por un lado, priva a la voluntad de su expresión -recordemos la importancia de la propiedad como forma de objetivación de la voluntad, como forma de determinarse como

\footnotetext{
${ }^{23}$ Se sugiere en este punto la lectura de Weber, Thadeu, "Right, Justice and Freedom in Hegel”, En Revista Textos \& Contextos, Vol. 13, núm. 1, 2014, pp. 9-19.

${ }^{24}$ Ver Ávila, Alexander \& Castellanos, Nilson, "La libertad y el derecho penal en Hegel. Una comprensión desde el derecho abstracto", En Revista VIA IURIS, N¹8, 2015, p. 95 .
} 
voluntad libre-, se niega a reconocer el derecho de esa voluntad particular. Atacando la cosa, se ataca a la voluntad pues es ella misma la que está puesta en esa cosa externa. De esta manera, al ser una coacción contra la expresión o existencia de la voluntad particular, el delito es, según Hegel, una violencia. Ahora bien, junto con ello, el delito también niega la voluntad común surgida del contrato. Para decirlo de otro modo: mediante un acto violento, el criminal niega el derecho de una voluntad particular a determinarse libremente, y al hacerlo, niega también el derecho en su totalidad. De ahí la tan citada frase hegeliana según la cual "el delito es un juicio negativamente infinito en su sentido completo" (\$ 95) -donde lo 'infinito' refiere a ese componente universal que la acción delictiva niega o ataca, el cual excede el derecho de tal o cual persona particular. Dice Hegel: “(...) no sólo se niega lo particular, la subsunción de una cosa a mi voluntad, sino también lo universal, lo infinito en el predicado de lo mío, es decir, la capacidad jurídica, sin la mediación de mi opinión (...)" (\$95). Esta cuestión resulta fundamental, pues permite observar que la oposición entre voluntad particular y voluntad universal (o, tal vez, deberíamos decir "voluntad común" ya que, según dijimos, las relaciones contractuales no permiten alcanzar una voluntad verdaderamente universal) se encuentra en el corazón del delito como negación del derecho.

\section{Sobre el problema de la pena}

\section{V.1. La pena como violencia segunda}

La lesión del derecho a través del crimen tiene para Hegel un carácter intrínsecamente nulo, pues esa negación presupone al derecho, y no es más que su contradicción. La aniquilación de la primera violencia, que es el crimen, a través de una segunda violencia, que es la pena, manifiesta esa nulidad intrínseca del acto mismo de negación del derecho. El crimen, en tanto ataque al derecho, en tanto negación del mismo, exige una contra-violencia que lo anule. Es sólo lesionando la voluntad particular del criminal a través del castigo que el derecho puede ser restituido (veremos que es un modo particular de restitución del derecho, y no la simple restitución del derecho abstracto) y volver a estar vigente, reestableciendo así la posibilidad de la realización de la libertad. Tal como sostiene Ricoeur, la visión de Hegel sobre el crimen y la pena se 
opone a una concepción netamente jurídica, donde tanto crimen como pena son considerados de manera independiente uno del otro, y no en función del punto de vista de la dialéctica. ${ }^{25}$ Según Hegel, en las diversas teorías modernas sobre la pena, el castigo aparece simplemente como algo irracional, pues es pensado como un mal que recae sobre un mal anterior, el delito. Al hacer hincapié en cuestiones vinculadas al potencial efecto disuasivo del castigo, a la corrección o a la intimidación del criminal, estas teorías incurren en un tratamiento subjetivo del crimen, se interesan por el daño particular que ese delito específico causó. Es por eso que, según Hegel, pierden de vista la consideración objetiva de la justicia y de la injusticia, aspecto sustancial en el tratamiento del delito y el castigo. Esto es, pierden de vista la consideración del crimen como violación o negación del derecho, o, dicho de otro modo, el carácter negativo que tiene la acción injusta, por más que se presente como una experiencia positiva. En este sentido, considerar el problema desde un punto de vista objetivo, le permite a Hegel pensar el castigo siempre como justo pues viene a anular una lesión al derecho en tanto derecho (el cual, como vimos, es una existencia de la libertad de la voluntad), y no sólo una lesión al derecho de una voluntad particular. El castigo deja ver que la determinación fundamental del delito es ese carácter infinito del cual hablábamos antes: el delito importa en tanto que lesión de lo universal.

Además de ser implícitamente justa, la pena es, para Hegel, también un derecho del criminal. Como persona racional que viola libremente el contrato, que se da existencia a sí misma como voluntad a través de su acción delictiva, el criminal es honrado como ser racional al recibir una pena (Obs. $\left.\int 100\right) .{ }^{26}$ Asimismo, el crimen contiene en sí cierto grado de racionalidad y de universalidad, pues crea “(...) una regla general que el delincuente, a través de su acto, reconoce como válida tanto para sí mismo como para cualquier otra

\footnotetext{
${ }^{25}$ Ver Ricoeur, Paul, "Historia de la idea de justicia/3. Hegel y el derecho penal", p. 205.

${ }^{26}$ Para una problematización sobre la imposibilidad de considerar a los dementes como criminales desde una perspectiva hegeliana, se sugiere ver Steinberger, Peter, "Hegel on Crime and Punishment", En The American Political Science Review, Vol. 77, N4, 1983, pp. 858-870.
} 
persona $(. .). " .{ }^{27}$ Es por eso que su comportamiento debe ser juzgado de acuerdo a esa regla general, independientemente de si el individuo es consciente o no de ello.

En línea con lo anterior, es posible afirmar que el rechazo de Hegel a un tratamiento subjetivo del crimen y del castigo, que piensa la administración de la pena ya sea como disuasión o prevención de futuros crímenes, ya sea como un método correctivo del criminal, tiene un doble aspecto. Por un lado, como vimos, Hegel remarca la imposibilidad que tiene tal tratamiento de ver la autocontradicción que el acto injusto en sí mismo implica, es decir, su nulidad intrínseca, a la cual referimos anteriormente. ${ }^{28}$ Pero, por otro lado, Hegel subraya la degradación a la que el criminal es sometido por estas teorías, las cuales le niegan racionalidad a su acción. El criminal no debe ser corregido ni tampoco disuadido de un posible nuevo delito, sino que debe ser castigado y bonrado en tanto ser que actúa racionalmente. Y es que, según Hegel, el criminal es una persona jurídica y, por ello, su accionar criminal debe ser considerado desde un punto de vista legal. ${ }^{29}$

En Hegel, el castigo es entonces justo (y lógicamente necesario) ${ }^{30}$ en estos dos sentidos: como aniquilación de la lesión del derecho en tanto derecho, y como honra al delincuente en tanto ser libre y racional. En este sentido, Hegel no sólo se opone a pensarlo como fundamentalmente disuasivo y/o correctivo como hemos visto, sino también a concebirlo en términos de mera compensación, esto es, de pensar la pena como equivalente a los daños infringidos por la acción injusta. Esta postura continúa siendo superficial según Hegel (y pertenece al ámbito del entendimiento) pues, al igual que en los casos

${ }^{27}$ Flechtheim, Ossip, "Hegel and the problem of punishment", Journal of the History of Ideas, Vol. 8, No3, 1947, p. 302 (traducción propia).

28 Para Hegel, esta imposibilidad da cuenta de que tales posturas permanecen en el ámbito del entendimiento, de la abstracción, en lugar de pasar al punto de vista de la razón. Este último implica la puesta en movimiento dialéctico de lo que el entendimiento fijó como instancias separadas - en nuestro caso, crimen y castigo. Ver Hegel, Georg Wilhelm Friedrich, La fenomenología del espiritu, Buenos Aires, FCE, 2015, p. 39. [Phänomenologie des Geistes, Felix Meiner, 1952]

${ }^{29}$ Ver Flechtheim, Ossip, "Hegel and the problem of punishment", p. 304.

30 Para un análisis sobre la necesidad e importancia del castigo en la perspectiva hegeliana, ver Steinberger, Peter, "Hegel on Crime and Punishment". 
anteriores, mira el daño particular causado por un delito específico, en lugar de mirar el delito como una forma de injusticia de carácter infinito. ${ }^{31}$ En tal sentido, el foco sobre la compensación del castigo fracasa en dar cuenta de la verdadera identidad entre crimen y pena. Esta identidad se funda sobre el concepto, por lo que no es una igualdad basada en la condición específica de la acción injusta, sino más bien una igualdad que les es implícita, que se funda de acuerdo con su valor (\$ 100). Tal como afirma Hegel, es el valor lo que permite acceder a lo universal en las cosas, para superar así las diferencias exteriores que éstas puedan presentar (hemos explorado brevemente esta cuestión al abordar el problema de la propiedad y el contrato). Si para Hegel la pena contiene un elemento de retribución, y puede graduarse según la ofensa, ${ }^{32}$ es porque la igualdad que comúnmente se observa entre un determinado delito y una determinada pena, igualdad que aparece como exterior, en realidad refleja una identidad interior: crimen y castigo están conectados pues el primero contiene en sí mismo al segundo como su negación, aunque todavía de manera abstracta. Es precisamente la punición la que le va a otorgar efectividad a dicha negación. En ese sentido, Ricoeur afirma que la contra-violencia de la pena es, en cierto modo, idéntica a la primera violencia (delito) que concurre a suprimir. Comprender esto es comprender la igualdad de ambas en términos de su valor, es decir, en términos de lo que hay de universal en ellas, y no por cierta equivalencia exterior que no es más que su manifestación superficial. Esta manifestación muestra la unión entre delito y pena como una unión arbitraria, sintética, entre una acción prohibida y un mal, entre un actuar injusto y un hacer sufrir, no permitiendo ver el lazo de razón que entre ellas existe. ${ }^{33}$ De manera

31 Recordemos que lo 'infinito' refiere a ese componente universal que la acción delictiva niega o ataca, el cual excede el derecho de tal o cual persona particular.

32 Desde el punto de vista del castigo, todos los delitos son para Hegel similares y comparables -aunque puedan ser diferentes en términos de su exterioridad-pues todos comportan lesiones a la noción misma de derecho, a esa voluntad común que surge de la relación contractual. Sus diferencias exteriores son las que permitirán que haya gradación en la punición -aspecto vinculado al ataque específico a una voluntad particular-, pero no es éste el aspecto sustancial en lo que a la naturaleza del crimen y la pena respecta.

${ }_{33}$ Ver Ricoeur, Paul, "Historia de la idea de justicia/3. Hegel y el derecho penal", p. 206. 
que, desde la perspectiva hegeliana, el método específico de castigo puede ser pensado en términos de disuasión o incluso de corrección; sin embargo, como vimos, estas consideraciones son completamente secundarias respecto de la verdadera naturaleza de la pena. "El castigo es esencialmente retributivo, y accidentalmente puede ser también preventivo, disuasivo, o reformador, como el caso específico lo requiera". 34

\section{V.2. La pena como justicia punitiva}

Si bien Hegel desarrolla los fundamentos de su teoría sobre delito y el castigo cuando analiza la esfera del derecho abstracto, no es sino con el advenimiento de la sociedad civil -específicamente de la administración de justicia- en el marco de las relaciones éticas, que la punición adquiere, según él, el carácter justo con el cual lo venimos describiendo. Es que, en la esfera de la inmediatez del derecho de la cual hemos dado cuenta, la eliminación del delito es una venganza (\$102). La venganza es para Hegel una justicia inmediata en la cual el acto de eliminación del crimen depende todavía de la voluntad subjetiva, y carece del elemento universal de la ley. En este sentido, "la venganza, pues; como acción positiva de una voluntad particular es una nueva violación" 35 que perpetúa la violencia en una cadena sin fin; el "mal infinito entra en escena y contamina la justicia", dirá Ricoeur. ${ }^{36}$ La imposición de la pena como acción de una voluntad subjetiva particular abre, cada vez, una nueva contradicción entre una violencia y una contra-violencia. Frente a ello, Hegel postula la necesidad de una justicia no vengadora, sino punitiva; una justicia que se encuentre librada de los intereses y formas subjetivas, y en la cual la voluntad subjetiva particular quiera lo universal como tal (\$103). Mediante este movimiento, la persona jurídica interioriza el derecho, lo convierte en algo interno, transformándose así en un sujeto moral. Hemos dejado la esfera del derecho abstracto para pasar a una nueva forma en que la voluntad se determina como

34 Dyde, Samuel Walters, "Hegel's conception of crime and punishment", en The Philosopbical Review, Vol. 7, Nº1, 1898, pp. 63-64 (traducción propia).

${ }^{35}$ Hegel, Georg Wilhelm Friedrich, Fundamentos de la filosofía del derecho, \$102, p. 141.

${ }^{36}$ Ver Ricoeur, Paul, "Historia de la idea de justicia/3. Hegel y el derecho penal”, p. 208. 
voluntad libre: la esfera del derecho de la voluntad subjetiva o moralidad. Es el propio movimiento dialéctico el que da lugar a esta nueva configuración de la voluntad que, en términos históricos, marca para Hegel el abandono de la Antigüedad y el comienzo de los tiempos modernos; es el momento del particular, o del para-sí [für sich]. Se comprende, entonces, que este pasaje, la superación de la voluntad libre en su inmediatez, implica, en primer lugar, que esta voluntad se oponga, niegue, la voluntad en sí, la voluntad común surgida producto del contrato. En términos de Cordua, "es el momento de la voluntad criminal". ${ }^{37}$ Pero, en segundo lugar, implica también una segunda negación a esta oposición, es decir, la negación de la primera negación (que es el crimen) mediante el castigo. De manera que, en Hegel, la teoría del delito y la pena es clave a la hora de comprender el pasaje a un segundo momento (analítico) en el proceso de determinación conceptual interna de la voluntad: la voluntad que es para sí [für sich]. Aquí, la internalización del derecho que posibilita la pena hace que la subjetividad moral pueda reconocer la violación de éste como una negación de sí misma, es decir, que quiera lo universal como algo propio suyo. Es la reflexión sobre el crimen como acto de una voluntad particular contra la ley universal lo que manifiesta, según Hegel, que ya no estamos frente a personas jurídicas sino frente a sujetos morales, sujetos en los que el componente de lo universal ya no se les presenta como algo externo a ellos mismos. En este sentido, "el concepto de libertad comienza a hacerse real en el individuo como sujeto moral, que en su particularidad quiere la ley moral o universal". 38

Ahora bien, hemos dicho que para que el castigo no permanezca como una mera venganza sin fin, el acto de supresión del delito debe incorporar el elemento universal de la ley. La persona debe interiorizar el derecho, convirtiéndose así en un sujeto moral. No obstante, el pasaje a la esfera de la moralidad subjetiva no basta para vencer este espíritu de venganza, es decir, el acto de supresión del delito fracasa en el intento de transformarse verdaderamente en pena. Y esto por cuanto, según Hegel, es únicamente en el marco de las relaciones éticas que éste se despoja de los motivos subjetivos y contingentes de la venganza, transformándose en pena, y posibilitando una

${ }^{37}$ Cordua, Carla, Explicación sucinta de la filosofía del derecho en Hegel, p. 86.

38 Amengual, Gabriel, "La moralidad como autodeterminación según Hegel”, Mayurqa, Vol. 22, N², 1989, p. 670. 
verdadera reconciliación del derecho consigo mismo. Es sólo de este modo que puede volverse justo en su existencia. Esta tarea no puede estar entonces conferida a la subjetividad moral que reflexiona sobre el crimen como acto de la voluntad particular contra la ley universal, sino a un poder público que represente lo universal vulnerado: el tribunal de justicia. De manera que el acto de castigo del delito sólo puede restituir la ley y realizar su validez en tanto se transforme en pena, y esto ocurre únicamente en el marco del Estado. Este proceso permite, asimismo, la reconciliación del criminal con la ley que conoce y encuentra válida para su propia protección (\$220). Ahora bien, cuando Hegel piensa el mundo ético, la concepción sobre el delito y el castigo planteada en la esfera del derecho abstracto no sufre transformaciones sustantivas. En el Estado, el acto de supresión del delito se transforma en pena propiamente dicha, pero, tal como sostiene Dyde, "la actitud del Estado hacia el crimen se encuentra resumida en el derecho abstracto". ${ }^{39} \mathrm{Y}$ es que, aun cuando en el marco del derecho abstracto había sido pensado como un momento preliminar y abstracto en la realización de la libertad, Hegel luego lo traslada a la esfera del Estado sin alteraciones, volviéndolo una función de la sociedad. ${ }^{40}$

El hecho de que, desde el punto de vista de la moralidad, el acto de eliminación de la acción injusta no logre despojarse del sentimiento subjetivo del interés particular (esto es, no logre hacerse valer como lo verdaderamente universal) sólo puede comprenderse si entendemos que, en Hegel, ésta refiere al momento formal de la autonomía de la voluntad, en el sentido kantiano. Dicho de otro modo, refiere al momento de la existencia de la libertad de la voluntad subjetiva, la cual se concreta en el 'derecho de apreciación de la acción', 'el derecho del bienestar' y el 'derecho de apreciación del Bien', pero no a una doctrina de los deberes y las virtudes. ${ }^{41}$ Es por eso que, si bien este momento marca la autodeterminación de la voluntad que así supera su primer momento conceptual de inmediatez (hemos visto el rol que tiene el castigo en ello), sigue siendo un momento subjetivo y formal que se superará en la

\footnotetext{
${ }^{39}$ Dyde, Samuel Walters, "Hegel's conception of crime and punishment", p. 70.

${ }^{40}$ Ibíd.

${ }^{41}$ Ver Amengual, Gabriel, "La filosofía del derecho de Hegel como filosofía de la libertad", Taula: quaderns de pensament, No10, 1988, pág. 101.
} 
eticidad. ${ }^{42}$ El derecho subjetivo como momento interior de autodeterminación ha perdido el punto de referencia exterior. En ese sentido, "la moralidad, por su carácter formal, solamente puede fundamentar la obligatoriedad del deber o lo abstracto del deber, pero no su determinación concreta. Para ello se requiere referirse no sólo a la voluntad subjetiva sino también a la comunidad en que convive", 43 esto es, a las instituciones éticas. La salida del "atolladero de la convicción subjetiva" 44 -para decirlo con palabras de Ricoeur-, del mundo de la interioridad que presenta el punto de vista de la moralidad, ocurre en Hegel por vía de la teoría del Estado, la cual habilitará la unión de estos elementos escindidos (mundo interior y exterior) que la voluntad para-si no puede unir. Esto le permitirá a la subjetividad recuperar el elemento de objetividad que en parte perdió al superar el primer momento de inmediatez y al volverse para-sí. Dicho en los términos de la dialéctica: el particular debe salir de su particularidad y volver a universalizarse, debe superarse en el universal concreto, tercer momento de la dialéctica hegeliana. Se comprende, entonces, por qué Hegel sostiene que es sólo en el marco de relaciones éticas que puede organizarse un cuerpo jurídico positivo válido que repose en normas que expresen el reconocimiento intersubjetivo fundado en la universalidad de la persona, universalidad que esté arraigada en prácticas concretas, y ya no meramente en deseos, exigencias y aspiraciones que permanecerían siempre impotentes. Una de las transformaciones que la superación [Aufhebung] del punto de vista de la moralidad trae consigo es, como vimos, la transformación

42 Para un desarrollo sobre la moralidad como momento de autodeterminación de la subjetividad, y sobre su superación en la forma de eticidad, se sugiere ver Amengual, Gabriel, "La moralidad como autodeterminación según Hegel". En este trabajo, el autor sostiene que los análisis sobre la Filosofía del Derecho hegeliana suelen poner poca atención sobre este momento por ser considerado "mera transición" del Derecho Abstracto a la Eticidad. No obstante, es ciertamente un momento tan relevante como los otros en el desarrollo dialéctico del concepto de libertad.

${ }^{43}$ Amengual, Gabriel, "La filosofía del derecho de Hegel como filosofía de la libertad", p. 101.

${ }^{44}$ Ricoeur, Paul, "Historia de la idea de justicia/3. Hegel y el derecho penal”, p. 210. 
del acto de supresión del delito propiamente en pena. Tal como afirma Mizrahi, es sólo así que el derecho abstracto deviene coactivo. ${ }^{45}$

\section{Comentarios finales}

A lo largo del presente trabajo hemos buscado realizar un acercamiento a los principales aportes de Hegel para pensar el problema del delito y la pena, intentando siempre remarcar la necesidad de hacerlo a la luz de su novedoso concepto de derecho en tanto "reino de la realización de la libertad", así como del movimiento dialéctico con el que piensa el continuo hacerse de las sociedades y los sujetos. Creemos que una lectura de estas características, esto es, una lectura que inscriba y conduzca este problema específico a los marcos conceptuales más generales con los que fue construido, no puede eludirse, aunque sea como punto de partida.

A modo de cierre, quisiéramos volver a remarcar dos cuestiones en relación con la problemática que aquí nos ha ocupado. En primer lugar, que, en la propuesta de Hegel, la disuasión del criminal respecto de acciones injustas, o incluso su corrección, resultan aspectos completamente secundarios para pensar el castigo por cuanto la pena, como segunda negación, remite a la restitución del derecho, pero ya no como derecho abstracto, sino como moralidad, es decir, como derecho de la voluntad subjetiva que lo ha interiorizado, y que quiere lo universal como algo propio. En segundo lugar, frente a este rechazo de las concepciones utilitaristas para explicar lo sustancial de este fenómeno, hemos intentado mostrar que el carácter retributivo que tiene la pena en Hegel no debiera entenderse como frecuentemente se entiende: antes bien, hemos visto que existe una identidad interior, un lazo de razón -en términos de Ricoeur-, que liga crimen y pena entre sí, y que sólo puede aprehenderse en el proceso dialéctico de desarrollo de la voluntad libre. Y, en línea con ello, la afirmación de que la pena en Hegel es racional implica entonces comprender que ésta corresponde a la superación [Aufhebung] del punto de vista

\footnotetext{
45 Para un análisis sobre el importante rol que juega la experiencia de lo ilícito para que el concepto de derecho adquiera carácter coactivo, ver Mizrahi, Esteban, "La legitimación hegeliana de la pena", Revista de Filosofía, Vol. 29, Nº1, 2004, pp. 7-31.
} 
de derecho abstracto, superación que posibilita la interiorización de lo común y, así, la transformación de personas jurídicas en sujetos morales. Asimismo, implica también reconocer que (conceptualmente) lo anterior no basta para que 'el castigo' sea verdaderamente justo, pues es preciso que sea el Estado quien legítimamente encarne lo universal, y transforme así en justicia punitiva lo que antes era justicia vengativa. Es decir, para ello se requiere del momento en que el sujeto moral pueda salir de la interioridad que lo caracterizaba desde el punto de vista de la moralidad, para universalizarse y recuperar así la referencia objetiva que su particularidad había perdido. Se trata de la superación [Aufbebung] de la moralidad por la eticidad. Lo anterior muestra que desentrañar el problema del delito y el castigo en Hegel es crucial (y no un problema entre otros) a la hora de comprender su propuesta en la Filosofía del Derecho, es decir, a la hora de entender el proceso de desarrollo dialéctico de la voluntad realmente libre (o, como vimos, también podríamos decir, el proceso de desarrollo del 'concepto de derecho').

Recibido: 05/2018; aceptado: 10/2018. 